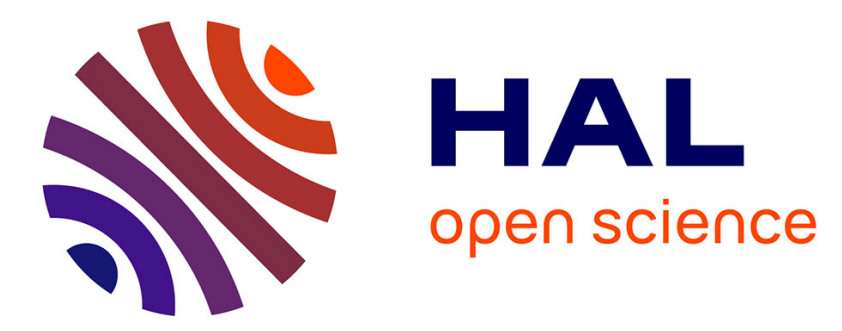

\title{
Synthesis of chiral supramolecular bisphosphinite palladacycles through hydrogen transfer-promoted self-assembly process
}

Alexandre Vasseur, Romain Membrat, Davide Palpacelli, Michel Giorgi, Didier Nuel, Laurent Giordano, Alexandre Martinez

\section{To cite this version:}

Alexandre Vasseur, Romain Membrat, Davide Palpacelli, Michel Giorgi, Didier Nuel, et al.. Synthesis of chiral supramolecular bisphosphinite palladacycles through hydrogen transfer-promoted selfassembly process. Chemical Communications, 2018, 54 (72), pp.10132 - 10135. 10.1039/c8cc06283h . hal-01870774

\section{HAL Id: hal-01870774 \\ https://hal.science/hal-01870774}

Submitted on 6 Apr 2019

HAL is a multi-disciplinary open access archive for the deposit and dissemination of scientific research documents, whether they are published or not. The documents may come from teaching and research institutions in France or abroad, or from public or private research centers.
L'archive ouverte pluridisciplinaire HAL, est destinée au dépôt et à la diffusion de documents scientifiques de niveau recherche, publiés ou non, émanant des établissements d'enseignement et de recherche français ou étrangers, des laboratoires publics ou privés. 


\title{
Synthesis of chiral supramolecular bisphosphinite palladacycles through hydrogen transfer- promoted self-assembly process $\dagger$
}

\author{
Alexandre Vasseur, (ID $\ddagger^{a}$ Romain Membrat, $\ddagger^{a}$ Davide Palpacelli, ${ }^{a}$ Michel Giorgi, (D) \\ Didier Nuel, (D) *a Laurent Giordano*a and Alexandre Martinez (iD *a
}

\begin{abstract}
$P$-Chiral secondary phosphine oxides react with $\mathrm{Pd}_{2}\left(\mathrm{dba}_{3}\right.$ in an acidic medium to provide chiral supramolecular bisphosphinite palladacycles through a $\mathrm{H}$-transfer-based self-assembly process prior to SPO-promoted oxidative addition of an acid to a $\mathrm{Pd}(0)$ centre. The one-pot methodology allows variations of the X-type ligand as desired. Eight complexes have been characterised by X-ray diffraction.
\end{abstract}

Supramolecular chemistry has witnessed huge growth due to a host of applications in a variety of areas including self-assembly phenomena. ${ }^{1}$ A broad spectrum of research in coordination has been conducted since supramolecular interactions are nowadays used to self-assemble ligands to tune the coordination spheres of metal catalysts. For instance, there is scope for the synthesis of supramolecular bidentate ligands through non-covalent interactions such as hydrogen bonding, coordinate bonding, and ionic bonding between two monodentate ligands. ${ }^{2}$ In this respect, secondary phosphine oxides (SPOs) have become an appealing preligand class owing to their potential for the construction of self-assembled bidentate ligands via hydrogen interaction. In concrete terms, the pentavalent tetracoordinated phosphorous form $\mathrm{P}(\mathrm{v})\left(\sigma^{4} \lambda^{5}\right)$ is usually in favourable tautomeric equilibrium with the trivalent tricoordinated phosphorous form, namely, phosphinous acid (PA) $\mathrm{P}(\mathrm{III})\left(\sigma^{3} \lambda^{3}\right)$. This equilibrium is shifted towards the trivalent phosphorous tautomer in the presence of a late transition metal via coordination through the unshared electron pair of the phosphorous atom (Scheme 1a). ${ }^{3}$ Although seldom exhibited, two cis-coordinated PAs arising from enantiopure SPOs may lead to a chiral six-membered hydrogen-bonded monoanionic diphosphorous chelate structure, ${ }^{4}$ resulting from the

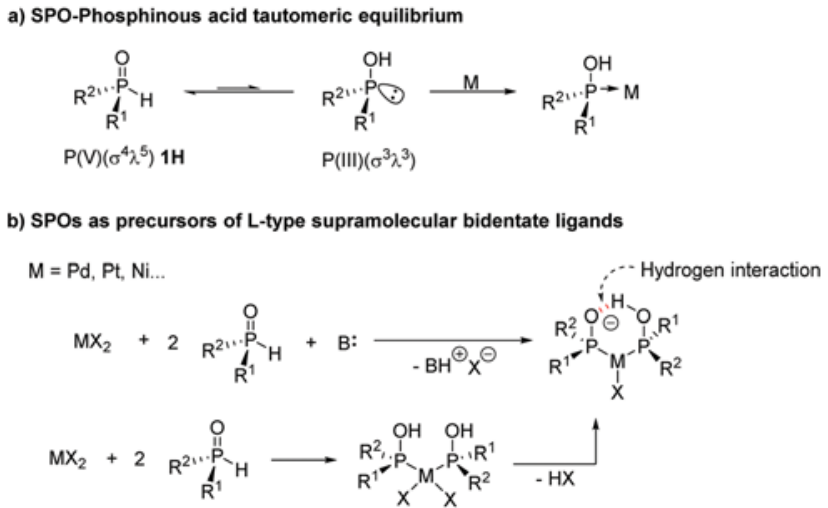

Scheme 1 Coordination of PAs to soft transition-metal centre.

deprotonation of one of the PAs by either an added base ${ }^{5}$ or the anionic X-type ligand dissociated from the metal (Scheme 1b). ${ }^{6}$

As bidentate ligands are of crucial importance to steer the selectivity outcome of a transition-catalysed reaction, it is thus not surprising that such PA-based supramolecular chelate structures are extensively used in homogenous catalysis ${ }^{7}$ with avant la lettre examples disclosed by Van Leeuwen as the backdrop. ${ }^{8}$ Achieving variations of the chelate structure seems rather straightforward as evidenced by the extensive available metal(II) complexes displaying relevant and subtle alterations of bite and cone angles by changing $\mathrm{R}^{1}$ and $\mathrm{R}^{2}$. In contrast, accessing complexes in which the anionic X-type ligand is different from chloride or acetate may be a challenging task since it heavily depends on the used starting metal(II) source (Scheme 1b). To date, this challenge necessitates either the presynthesis of a noncommercial metal(II) starting source or subsequent additional synthetic steps from appropriately chosen home-prepared PA-based metallacycles such as the silver salt-promoted substitution of the chloride ligand of $\left[\operatorname{Pd}\left\{(\mathbf{1})_{2} \mathrm{H}\right\}\right]_{2}(\mu-\mathrm{Cl})_{2}$ when more original palladacycles are desired. ${ }^{3}$ Given the influence of this ligand type on the course of Pd-catalysed reactions, ${ }^{9}$ developing a one-pot method that allows direct access to any supramolecular bisphosphinite palladacycles appears highly desirable but is a huge challenge. 


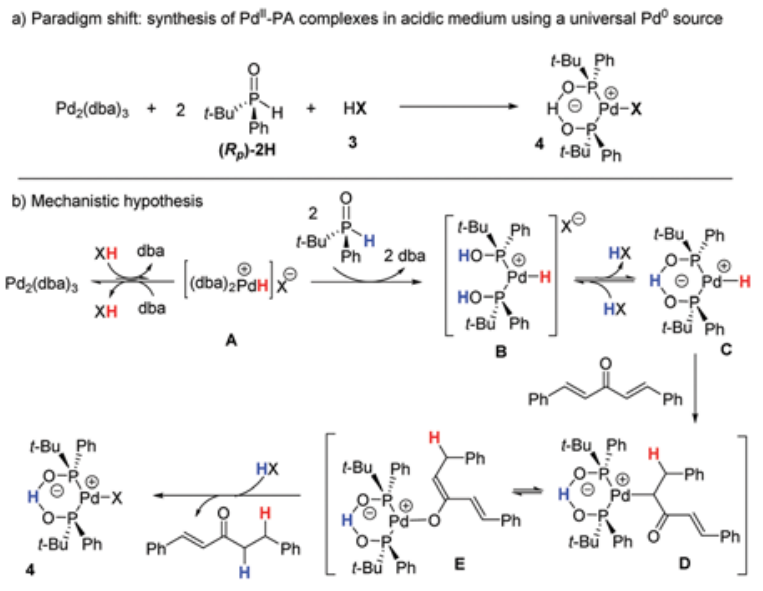

Scheme 2 Proposed strategy.

Our solution to tackle this salient issue relies on a paradigm shift, namely, operating in acidic conditions rather than basic or neutral conditions (Scheme 2a versus Scheme 1b) with the hydrogen transfer concept as Ariadne's thread. Let us consider commercially available $\mathrm{Pd}_{2}(\mathrm{dba})_{3}$ as a universal source for such complexes $^{10}$ (Scheme 2b). One can assume that the treatment of $\mathrm{Pd}_{2}(\mathrm{dba})_{3}$ with an acid HX would lead to the complex $\mathbf{A}$ resulting from an oxidative addition step. ${ }^{11}$ Coordination of two PAs $\left(\boldsymbol{R}_{\mathbf{p}}\right)-\mathbf{2 H}$ to the metal(II) centre would then be needed to avoid the unfavourable equilibrium associated with such a chemical event and would therefore provide the complex $\mathbf{B}$. The counter-ion-promoted deprotonation of one of the two PAs would thereafter allow the formation of the supramolecular bisphosphinite hydrido-palladacycle $\mathbf{C}$. Insertion of one of the two double bonds of dba into the H-Pd bond would then afford the organopalladium species $\mathbf{D}$ in supramolecular ligandpromoted equilibrium with the palladium enolate $\mathbf{E}$ via oxa- $\pi$ allylpalladium. ${ }^{12}$ The ionic character of the O-Pd bond would eventually favour heterolytic fission through acidolysis to provide the expected complex 4 . If successful, this entirely self-assembled approach would surely represent a significant advancement in the field since it would potentially grant access to a new illusory contour library.

Fortunately, treating $\mathrm{Pd}_{2}(\mathrm{dba})_{3}$ with propionic or cyclopropanecarboxylic acid at $60{ }^{\circ} \mathrm{C}$ in the presence of the easily prepared enantioenriched $\left(R_{\mathrm{p}}\right)-t$-butyl(phenyl)phosphine oxide $\left(\boldsymbol{R}_{\mathrm{p}}\right)-\mathbf{2} \mathbf{H}^{13}$ and toluene as the solvent led to complexes $\mathbf{4 a}$ and 4b, respectively, in good yields (Table 1). ${ }^{31} \mathrm{P}\left\{{ }^{1} \mathrm{H}\right\}$ NMR analysis in $\mathrm{CDCl}_{3}$ of the crude mixture revealed a single resonance at $\delta 95.5$ and $95.6 \mathrm{ppm}$, suggesting the presence of a single diastereomer. Interestingly, our hydrogen-transfer-based transformation proceeded smoothly when a phenylthio group-containing carboxylic acid compound was involved despite well-known ligand properties (please see 4c). Aromatic carboxylic acid substrates were also subjected to this $\mathrm{Pd}(0)$-mediated self-assembly process (see $\mathbf{4 d} \mathbf{d}-\mathbf{f}$ ). It should be stressed that our chemical reactions left the $\mathrm{C}-\mathrm{Cl}$ and $\mathrm{C}-\mathrm{Br}$ bonds intact, highlighting the high selectivity of the method towards the carboxylic acid moiety. The method was also compatible with polyfused aromatic as well as heteroaromatic
Table 1 Scope of the process ${ }^{a}$

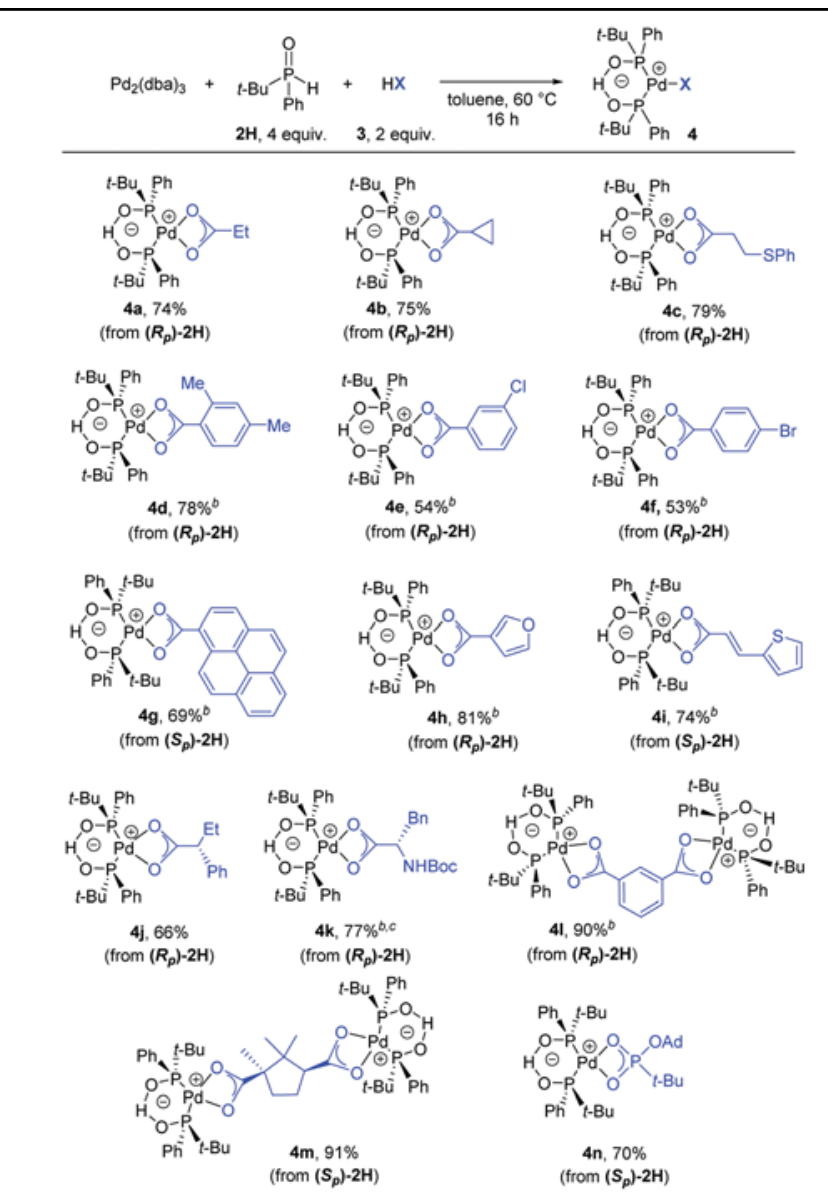

${ }^{a}$ Reaction conditions: $\mathrm{Pd}_{2}(\mathrm{dba})_{3}(0.1 \mathrm{mmol}), 2 \mathrm{H}(0.4 \mathrm{mmol}), 3(0.2 \mathrm{mmol})$, toluene $(5 \mathrm{~mL}), 60^{\circ} \mathrm{C}, 16 \mathrm{~h}$; yields of the isolated complexes are reported. ${ }^{b}$ Structurally characterised by X-ray diffraction analysis. ${ }^{c}$ Slightly contaminated with a side-complex formed during the purification step.

caroboxylic acid compounds ( $\mathbf{4 g}$ and $\mathbf{4 h}-\mathbf{i}$, respectively). It is worthy of note that $\mathbf{4 i}$, in which the chemical integrity of the double bond is preserved, could be isolated in $74 \%$ yield although $(E)-3-(2-$ thienyl)acrylic acid could also play the role of a H-acceptor. Under the same conditions, using (2R)-phenylbutyric acid or $N$-Boc-Lphenylalanine led to $\mathbf{4 j}$ and $\mathbf{4 k}$, respectively, for which both L-type and X-type ligands were chiral. It should be stressed that $\mathbf{4 j}$ showed promising activity in the asymmetric isomerisation reaction of allylic alcohols (ESI $\dagger$ ). When the reaction was conducted with dicarboxylic acids, dinuclear supramolecular architectures were obtained in excellent yields. Also, the use of isophtalic acid allowed the formation of the symmetrical supramolecular structure $4 \mathbf{l}$; the use of (+)-camphoric acid resulted in the formation of the chiral unsymmetrical structure $\mathbf{4 m}$, possessing six stereogenic centres. Lastly, our developed self-assembly approach was not restricted to carboxylic acids as it could be extended to alkyl H-phosphonate (please see $4 \mathbf{n}$ ). This can pave the way for the synthesis of selfassembled hybrid catalysts comprising a metal catalyst and an organocatalyst masked as an X-type ligand of the metal.

Eight complexes were structurally characterised by singlecrystal X-ray diffraction analysis. X-ray crystallography confirmed 


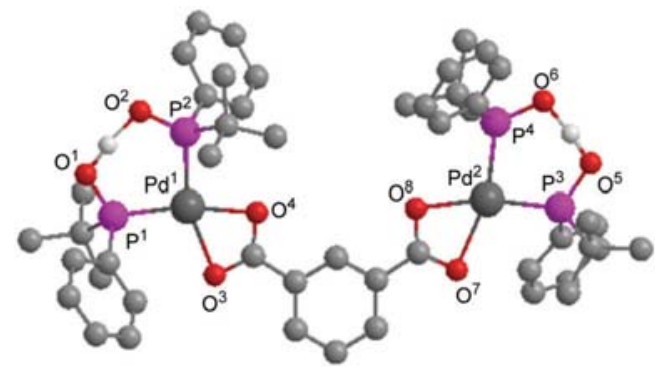

Fig. 1 Ball and stick plot of the crystal structure of $4 \mathrm{l}$ with most hydrogens omitted for clarity. Selected bond lengths ( $(\AA)$ and angles $\left({ }^{\circ}\right)$ Pd1-P1 2.240(13), Pd1-P2 2.229(12), Pd1-O3 2.247(3), Pd1-O4 2.111(3), Pd2-P3 2.225(13), Pd2-P4 2.235(12), Pd2-O7 2.220(3), Pd2-O8 2.165(4), P1-O1 1.557(3), P2-O2 1.527(4), P3-O5 1.551(3), P4-O6 1.529(4), O3-C21 1.258(5), O4-C21 1.271(5), O7-C28 1.273(5), O8-C28 1.290(5), P2-Pd1-P1 90.94(5), O4-Pd1-O3 60.29(12), P3-Pd2-P4 91.32(5), O8-Pd2-O7 60.46(12).

that our hypothetical chemical sequence occurred with retention of configuration at the phosphorous atom despite the required temperature $\left(60{ }^{\circ} \mathrm{C}\right)$ and acidic reaction conditions. Also, they displayed a $\left[\mathrm{LL}^{\prime} \mathrm{Pd}\left(\mathrm{k}^{2}\right.\right.$-OOCR $)$-like general formula, where $\mathrm{LL}^{\prime}$ is a $\sigma$-donor supramolecular bidentate L-type ligand. As a rule, the four-membered $\mathrm{M}-\mathrm{O}-\mathrm{C}-\mathrm{O}$ chelate is prone to overcoming an opening as a result of an incoming ligand. ${ }^{14}$ These $\kappa^{2}$-OOCR palladium structures are often suspected as key intermediates in catalytic reactions ${ }^{15}$ and are sometimes detected in solution ${ }^{16}$ or gas phase ${ }^{17}$ but are seldom structurally characterised owing to their propensity to form oligomeric carboxylate-bridged structures. ${ }^{14}$ To the best of our knowledge, only a very small number, with $\mathrm{R}$ limited to a methyl or trifluoromethyl group, has been fully characterised. ${ }^{6 b, 18}$ Even rarer are the structurally characterised dinuclear complexes $\left\{\left(\mathrm{LL}^{\prime}\right)_{2} \mathrm{Pd}_{2}\left[\mathrm{k}^{2}-(\mathrm{OOC})_{2} \mathrm{R}\right]\right\}$. Fig. 1 provides a unique example in this regard.

The crystallographic data of $\mathbf{4 l}$ and other structurally characterised complexes show that the metal centres are located in a distorted square-planar structure with bite angles of $91.1^{\circ}$ and $60.4^{\circ}$ on average for PA-based and benzoate bidentate ligands, respectively. The average $\mathrm{C}-\mathrm{O}$ bond length of carboxylate moieties $(1.273 \AA)$ is approximately between those of C-O single ( $1.43 \AA)$ and double bonds $(1.22 \AA)$ and is thus in accordance with partial double bond character. The short distance between the oxygen atoms $\mathrm{O}^{1}-\mathrm{O}^{2}$ and $\mathrm{O}^{5}-\mathrm{O}^{6}$ (2.405 $\AA$ on average) and the absence of $\nu_{\mathrm{OH}}$ in the $3000-3500 \mathrm{~cm}^{-1}$ region indicate strong and symmetrical $\mathrm{O}-\mathrm{H}-\mathrm{O}$ bonding. ${ }^{4,19}$ In addition, the $\mathrm{P}-\mathrm{O}$ bond lengths (in the range of 1.527-1.557 $\AA$ ) are significantly longer than typical $\mathrm{P}=\mathrm{O}$ lengths (in the range of $1.48-1.50 \AA$ )..$^{20}$ These observations are in agreement with the presence of $\mathrm{H}$ bonds assisted by a negative charge ${ }^{21}$ spread out between the two oxygen atoms of the supramolecular six-membered diphosphorous chelate structure. In any case, the $\mathrm{Pd}-\mathrm{O}$ bond lengths are significantly shorter than those reported for the $\operatorname{Pd}\left(\mathrm{K}^{2}\right.$-acetato $)\left[(\mathbf{1})_{2} \mathrm{H}\right]$ analogous complex $\left(\mathrm{R}^{1}=\mathrm{R}^{2}=\right.$ adamantyl or diadamantyl), whereas the Pd-P distances are longer, ${ }^{6 b, 18 a}$ presumably due to the less pronounced $\pi$-acceptor character of PAs involved in the latter.

Considering all the structural features of such architectures, we lastly investigated the mechanism. As our mechanistic
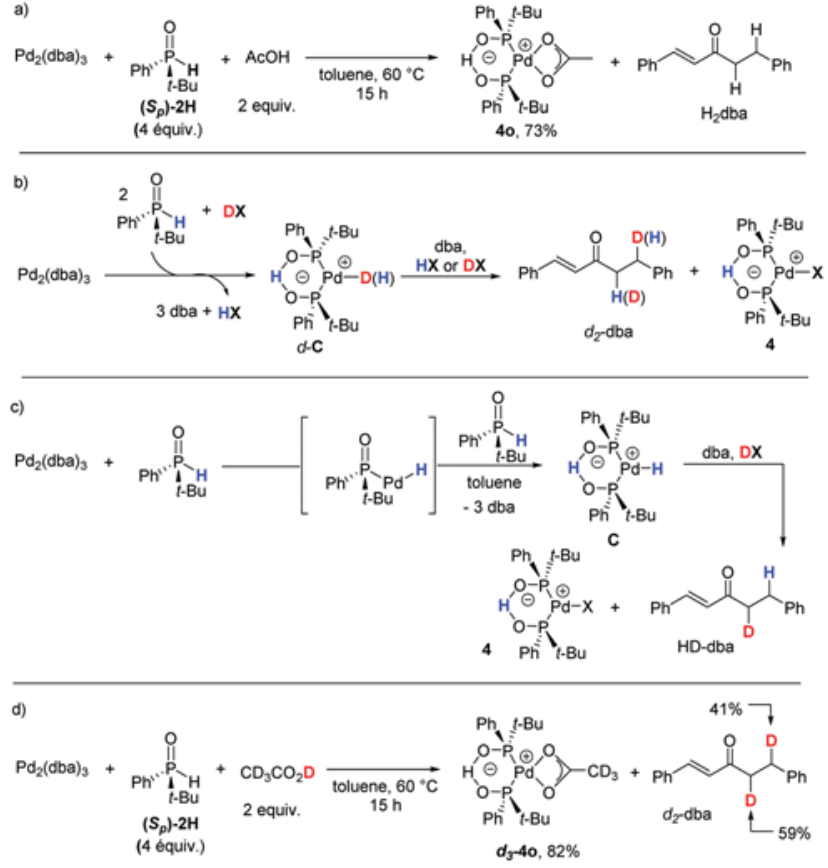

Scheme 3 Mechanistic investigation.

rationale was based on Pd-mediated $\mathrm{H}$-transfer to dba ligands of the starting metal source, we first sought to highlight the production of $\mathrm{H}_{2} \mathrm{dba}$ concomitantly with the formation of our supramolecular complexes. As hypothesised, the treatment of $\mathrm{Pd}_{2}(\mathrm{dba})_{3}$ with acetic acid in the presence of $(\boldsymbol{S p})-\mathbf{2} \mathbf{H}$ afforded both the complex 40 in $73 \%$ yield and the expected monoreduced adduct $\mathrm{H}_{2} \mathrm{dba}$ (Scheme $3 \mathrm{a}$ ) under the same conditions as those previously utilised.

We then assumed that this key step would be preceded by the formation of the 14-electron species $\mathbf{C}$ resulting from the oxidative addition of an acid $\mathrm{HX}$ to $\operatorname{Pd}(0)$ followed by the cis-coordination of two (Sp)-2H. If true, performing the same reaction with deuterium-labelled acid DX instead of HX would lead to the formation of $d_{2}$-dba with equal deuterium incorporation rates at the $\alpha$ and $\beta$ positions of the ketone (Scheme 3b). Indeed, once $\boldsymbol{d}$-C is formed by the consumption of a molecule of DX, a molecule of HX should be released and can therefore compete with the former. Alternatively, $\mathbf{C}$ might also result from the oxidative addition of $(\mathbf{S p})-2 \mathrm{H}$ to $\mathrm{Pd}(0)$ and subsequent coordination of an additional $(\boldsymbol{S p})-\mathbf{2} \mathbf{H}$ to the metal centre, which is similar to that reported by Tanaka et al. for the $\operatorname{Pd}(0)$-catalysed hydrophosphinylation of alkynes in the presence of symmetrical diphenylphosphine oxide. ${ }^{22}$ This option would consequently afford HD-dba as a co-product of $\mathbf{4}$, in which deuterium would be exclusively located at the $\alpha$ position of the ketone (Scheme 3c). The reaction of $\operatorname{Pd}_{2}(\mathrm{dba})_{3}$ with $d_{6}$-acetic acid yielded $\boldsymbol{d}^{3}$-4o and $d_{2}$-dba with deuterium incorporation rates of $59 \%$ and $41 \%$ at the $\alpha$ and $\beta$ positions of the ketone, respectively (Scheme 3d). This clearly supported the mechanistic pathway involving oxidative addition of the acid to the metal. The unequal distribution can be rationalised by $\mathrm{KIE},{ }^{23}$ which should be more significant for the oxidative addition step than for the acidolysis step, the former 
being presumably the rate determining step owing to the associated unfavourable equilibrium. ${ }^{11}$

To conclude, we developed a self-assembling method, allowing the production of supramolecular chiral bisphosphinite palladacycles for which a $\kappa^{2}$-coordinated X-type ligand seemed to be modifiable as desired. For the first time, the proposed approach was based on the use of a universal $\operatorname{Pd}(0)$ source. Our mechanistic study suggested that phosphinous acids as ligands are prone to stabilising intermediates resulting from the oxidative addition of an acid to a $\operatorname{Pd}(0)$ metal centre. Eight complexes were structurally characterised by X-ray diffraction analysis including unusual chiral dinuclear species. Crystallographic data showed that the coordination of phosphinous acids to $\mathrm{Pd}(\mathrm{II})$ occurred with the retention of configuration at the $\mathrm{P}$ atom despite the used temperature and the acidic reaction medium.

1 For recent reviews, see: (a) M. Liu, L. Zhang and T. Wang, Chem. Rev., 2015, 115, 7304-7397; (b) M. D. Ward and P. R. Raithby, Chem Soc. Rev., 2013, 42, 1619-1636; (c) M. M. Safont-Sempere, G. Fernández and F. Würthner, Chem. Rev., 2011, 111, 5784-5814.

2 For relevant reviews, see: (a) M. Raynal, P. Ballester, A. Vidal-Ferran and P. W. N. M. van Leeuwen, Chem. Soc. Rev., 2014, 43, 1660-1733; (b) P. Ballester, P. W. N. M. van Leeuwen and A. Vidal, in Comprehensive Inorganic Chemistry II: From Elements to Applications, ed. J. Reedijk and K. Poeppelmeier, Elsevier, Oxford, 2013, vol. 6, pp. 45-486; (c) R. Bellini, J. I. van der Vlugt and J. N. H. Reek, Isr. J. Chem., 2012, 52, 613-629; (d) S. Carboni, C. Gennari, L. Pignatoro and U. Piarulli, Dalton Trans., 2011, 40, 4355-4373; (e) J. Meeuwissen and J. N. H. Reek, Nat. Chem., 2010, 2, 615-621.

3 N. V. Dubrovina and A. Börner, Angew. Chem., Int. Ed., 2004, 43, 5883-5886.

4 Two examples: (a) A. Gallen, S. Orgué, G. Muller, E. C. EscuderoAdán, A. Riera, X. Verdaguer and A. Grabulosa, Dalton Trans., 2018, 47, 5366-5379; (b) E. Y. Y. Chan, Q.-F. Zhang, Y.-K. Sau, S. M. F. Lo, H. H. Y. Sung, I. D. Williams, R. K. Haynes and W.-H. Leung, Inorg. Chem., 2004, 43, 4921-4936.

5 (a) B. Kurscheid, B. Neumann, H.-G. Stammler and B. Hoge, Chem. Eur. J., 2011, 17, 14935-14941; (b) D. Martin, D. Moraleda, T. Achard, L. Giordano and G. Buono, Chem. - Eur. J., 2011, 17, 12729-12740; (c) T. Achard, L. Giordano, A. Tenaglia, Y. Gimbert and G. Buono, Organometallics, 2010, 29, 3936-3950.

6 (a) M. S. Balakrishna, D. Suresh, P. Kumar and J. T. Mague, J. Organomet. Chem., 2011, 696, 3616-3622; (b) L. Ackermann,
H. K. Potukuchi, A. Kapdi and C. Schulke, Chem. - Eur. J., 2010, 16, 3300-3303; (c) L.-Y. Jung, S.-H. Tsai and F.-E. Hong, Organometallics, 2009, 28, 6044-6053; (d) J. Bigeault, L. Giordano and G. Buono, Angew. Chem., Int. Ed., 2005, 44, 4753-4757.

7 For reviews, see: $(a)$ T. Achard, Chimia, 2016, 70, 8-19; $(b)$ T. M. Shaikh, C.-M. Weng and F.-E. Hong, Coord. Chem. Rev., 2012, 256, 771-803; (c) L. Ackermann, Isr. J. Chem., 2010, 50, 652-663; (d) L. Ackermann, Synthesis, 2006, 1557-1571.

8 (a) P. W. N. M. van Leeuwen and C. F. Roobeek, Eur. Pat. Appl., EP 82576, 1983; Chem. Abstr., 1983, 99, 121813; (b) P. W. N. M. van Leeuwen, C. F. Roobeek, R. L. Wife and J. H. G. Frijns, J. Chem. Soc., Chem. Commun., 1986, 31-33; (c) P. W. N. M. van Leeuwen, C. F. Roobeek, J. H. G. Frijns and A. G. Orpen, Organometallics, 1990, 9, 1211-1222; (d) P. W. N. M. van Leeuwen and C. F. Roobeek, New J. Chem., 1990, 14, 487-493; (e) P. W. N. M. van Leeuwen, C. F. Roobeek and A. G. Orpen, Organometallics, 1990, 9, 2179-2181.

9 For instance, the in situ generation of a hindered $\mathrm{Pd}(\mathrm{II})$ pivalate from $\operatorname{Pd}($ II) acetate prevents competitive occupation of vacant sites in the Pd-catalysed benzene arylation, see: M. Lafrance and K. Fagnou, J. Am. Chem. Soc., 2006, 128, 16496-16497.

10 Although the Pd:dba ratio is often different from $2: 3$, the common formula $\mathrm{Pd}_{2}(\mathrm{dba})_{3}$ was chosen, see: S. S. Zalesskiy and V. P. Ananikov, Organometallics, 2012, 31, 2302-2309.

11 C. Amatore, A. Jutand, G. Meyer, I. Carelli and I. Chiarotto, Eur. J. Inorg. Chem., 2000, 1855-1859.

12 A. Vasseur, R. Membrat, D. Gatineau, A. Tenaglia, D. Nuel and L. Giordano, ChemCatChem, 2017, 9, 728-732.

13 D. Gatineau, D. H. Nguyen, D. Hérault, N. Vanthuyne, J. Leclaire, L. Giordano and G. Buono, J. Org. Chem., 2015, 80, 4132-4141.

14 M. E. Moret, S. F. Keller, J. C. Slootweg and P. Chen, Inorg. Chem., 2009, 48, 6972-6978.

15 (a) G. Gerdes and P. Chen, Organometallics, 2004, 23, 3031-3036; (b) W. A Herrmann, C. Brossmer, C.-P. Reisinger, T. H. Riermeier, K. Ofele and M. Beller, Chem. - Eur. J., 1997, 3, 1357-1364; (c) W. A. Herrmann, C. Brossmer, K. Ofele, C.-P. Reisinger, T. Piermeier, M. Beller and H. Fischer, Angew. Chem., Int. Ed. Engl., 1995, 34, 1844-1848.

16 S. G. Fiddy, J. Evans, M. A. Newton, T. Neisius, R. P. Tooze and R. Oldman, Chem. Commun., 2003, 2682-2683.

17 M. Woolley, G. N. Khairallah, G. da Silva, P. S. Donnelly and R. A. J. O'Hair, Organometallics, 2014, 33, 5185-5197.

18 (a) D. Ghorai, V. Müller, H. Keil, D. Stalke, G. Zanoni, B. A. Tkachenko, P. R. Schreiner and L. Ackermann, Adv. Synth. Catal., 2017, 359, 3137-3141; (b) N. Thirupathi, D. Amoroso, A. Bell and J. D. Protasiewicz, Organometallics, 2005, 24, 4099-4102; (c) M. S. Viciu, E. D. Stevens, J. L. Petersen and S. P. Nolan, Organometallics, 2004, 23, 3752-3755; (d) J.-C. Lee, M.-G. Wang and F.-E. Hong, Eur. J. Inorg. Chem., 2005, 5011-5017.

19 D. V. Naik, G. J. Palenki, S. E. Jacobson and A. J. Carty, J. Am. Chem. Soc., 1974, 96, 2286-2288.

20 (a) G. Annibale, P. Bergamini, V. Bertolasi, E. Besco, M. Cattabriga and R. Rossi, Inorg. Chim. Acta, 2002, 333, 116-123; (b) N. J. Goodwin, W. Henderson and B. K. Nicholson, Inorg. Chim. Acta, 2002, 335, 113-118.

21 P. Gilli, V. Bertolasi, V. Ferretti and G. Gilli, J. Am. Chem. Soc., 1994, 116, 909-915.

22 L.-B. Han, N. Choi and M. Tanaka, Organometallics, 1996, 15, 3259-3261.

23 (a) N. S. Isaacs, Tetrahedron Lett., 1965, 6, 4549-4551; (b) N. S. Isaacs, Tetrahedron Lett., 1965, 6, 4553-4555. 